Article

\title{
Utilization of Scatterplot Smoothers to Understand the Environmental Preference of Bigeye Tuna in the Southern Waters off Java-Bali: Satellite Remote Sensing Approach
}

\author{
Martiwi Diah Setiawati ${ }^{1, *}$ and Tasuku Tanaka ${ }^{2,3}$ \\ 1 Integrated Research System for Sustainability Sciences (IR3S), The University of Tokyo Institutes for \\ Advanced Studies (UTIAS), The University of Tokyo, Tokyo 113-8654, Japan \\ 2 Center for Remote Sensing and Ocean Science (CReSOS), Udayana University, Denpasar-Bali 80232, \\ Indonesia; tttanaka@yamaguchi-u.ac.jp \\ 3 Graduate School of Science and Engineering, Department of Environmental Science and Engineering, \\ Yamaguchi University, Ube 755-8611, Japan \\ * Correspondence: martiwi1802@gmail.com; Tel.: +81-358-411-545
}

Academic Editor: Maria Angeles Esteban

Received: 4 October 2016; Accepted: 26 January 2017; Published: 9 February 2017

\begin{abstract}
The southern waters off Java-Bali were recognized as spawning and potential fishing ground for tuna species. However, few studies have been conducted on this area. In this paper, the environmental preference of bigeye tuna was assessed based on catch data and three main environmental satellite data; namely; sea surface temperature (SST), sea surface chlorophyll (SSC), and sea surface height deviation (SSHD). Then, the relationship between bigeye tuna catches and environmental satellite data was analyzed by using a simplified method of the Generalized Additive Model (GAM) which is called scatterplot smoothers. This method is the forerunner of GAM and has not yet been applied for fisheries analysis. The aim of this study was to evaluate its performance for/in analyzing bigeye tuna habitat preference. The result indicated that SST, SSC, and SSHD had a high correlation with the bigeye tuna's spatial patterns. Furthermore, spatial patterns of bigeye tuna preference display typical characteristics of low SST, low SSC, and low positive SSHD as well as areas with extreme SSHD values, which are almost the same results as those identified with GAM analysis in the same study area.
\end{abstract}

Keywords: scatterplot smoothers; Southern Waters off Java-Bali; sea surface temperature; sea surface chlorophyll; sea surface height deviation

\section{Introduction}

The Indian Ocean is the second biggest tuna fishery industry, and it contributes $26 \%$ of the world's catches [1]. Bigeye tuna (Thunnus obesus) is one of the tuna species which has high commercial value in the Eastern Indian Ocean [2], and it contributes $24 \%$ of the total catches of the four species of tuna in Indonesia [3]. This species displays large longitudinal movement between $40^{\circ} \mathrm{S}$ and $40^{\circ} \mathrm{N}$, especially in tropical waters $[4,5]$. They prefer to stay at the temperature around the thermocline layers, and they have a high tolerance of water temperature [6]. Moreover, bigeye tuna are considered a visual predator, which means that they favor staying in clear water [5]. The main depth of fishing for bigeye tuna in the Indian Ocean is between 161-280 $\mathrm{m}$ [7], although they can stay in the surface layer (0-100 $\mathrm{m})$ at night time [4].

Explorations to assess Eastern Indian Ocean characteristics have been undertaken for the last 50 years [8], but linkages with tuna fisheries have rarely been studied. The Eastern Indian Ocean, 
particularly in the southern waters off Java-Bali, has a semi-permanent coastal upwelling which annually arises from June to October [9,10]. This phenomenon is mainly generated by Ekman transport, associated with the monsoonal system [11], and it is the dominant factor influencing the ocean properties such as sea surface temperature (SST), the sea surface chlorophyll (SSC), and the sea surface height deviation (SSHD) variability. In addition, these features can be used to infer a productive frontal zone (i.e., important habitat structure) for tuna [12]. However, the frontal zones around tropical oceans are difficult to recognize due to their low variability. The Indonesian seas are the only major low-latitude connection in the global oceans [13]. This connection permits the transfer of Western Pacific waters to the Indian Ocean by the Indonesia Through Flow (ITF) through the Lombok strait and the Ombai Strait [14]. As a result, unique distributions of physical and biogeochemical parameters in the southern part of Java-Bali have been created [14]. In addition, mesoscale eddies and inter-annual variations associated with the Indian Ocean Dipole (IOD) and the Pacific El Niño/Southern Oscillation (ENSO) strongly modify seasonal variations over a large part of the Eastern Indian Ocean. Furthermore, upwelling and offshore transport of the ITF outflow have important implications for offshore fisheries, including the surface waters of the Indo-Australian basin region $[15,16]$. These are caused by offshore transport of the coastal upwelling injecting plankton rich water into this key spawning area.

The ocean environmental properties play a crucial role in regulating bigeye tuna distribution and abundance [12]. Moreover, the near real-time data of ocean properties can be obtained from satellite remote sensing. In recent years, satellite remote sensing has been developed as an instrumental tool in ecology for monitoring purposes [17] and has been used to manage fisheries at sustainable levels [18]. Reliable global ocean coverage of SST, SSC, and SSHD has been provided by satellite remote sensing data which has high spatial and temporal resolution [19]. Satellite remote sensing applications for fisheries have been increasing worldwide (e.g., [20-25]). Thus, oceanographic phenomena such as front, eddies, ENSO, and IOD are often used to determine the preferred habitat and potential fishing grounds $[6,17,26,27]$. However, the study of tuna fisheries ecology by satellite remote sensing is relatively uncommon in the study area $[21,25,28,29]$. Previous researchers stated that the ocean properties had not influenced the number of bigeye tuna [22,29], while other researchers reported that ocean properties influence the existence of bigeye tuna based upon their results from using a generalized additive model (GAM) in the study area [21,25]. GAM was commonly used to evaluate the relationship between environmental variables and tuna distribution [12,21,25,30,31]. However, GAM requires complex knowledge and equations. Scatter plot smoothers is the forerunner of GAM [32] and was developed by Tibshirani and Hastie (1986). This method was conducted to determine the relationship between tuna presence and environmental variables. However, this method has not applied yet for fisheries. By applying scatter plot smoothers, the readers can understand how to calculate GAM step by step, and the interpretation is easier to understand. Furthermore, other researchers have conducted cluster analysis and principal component analysis (PCA) to measure tuna habitat characteristics on global scales as well as in the Gulf Mexico [33,34]. PCA was conducted to decide the weight/score of each parameter in order to build a potential habitat map by using ArcGIS. In this study, we combined scatterplot smoothers and PCA to determine the potential habitat of bigeye tuna. The combination between scatterplot smoothers and PCA were able to build the preferred habitat analysis while introducing less subjectivity.

\section{Method}

\subsection{Study Area}

The study area was located in the southern waters off Java-Bali which is between $10^{\circ} \mathrm{S}$ to $18^{\circ} \mathrm{S}$ latitude and $110^{\circ} \mathrm{E}$ to $118^{\circ} \mathrm{E}$ longitude, as shown in Figure 1. 


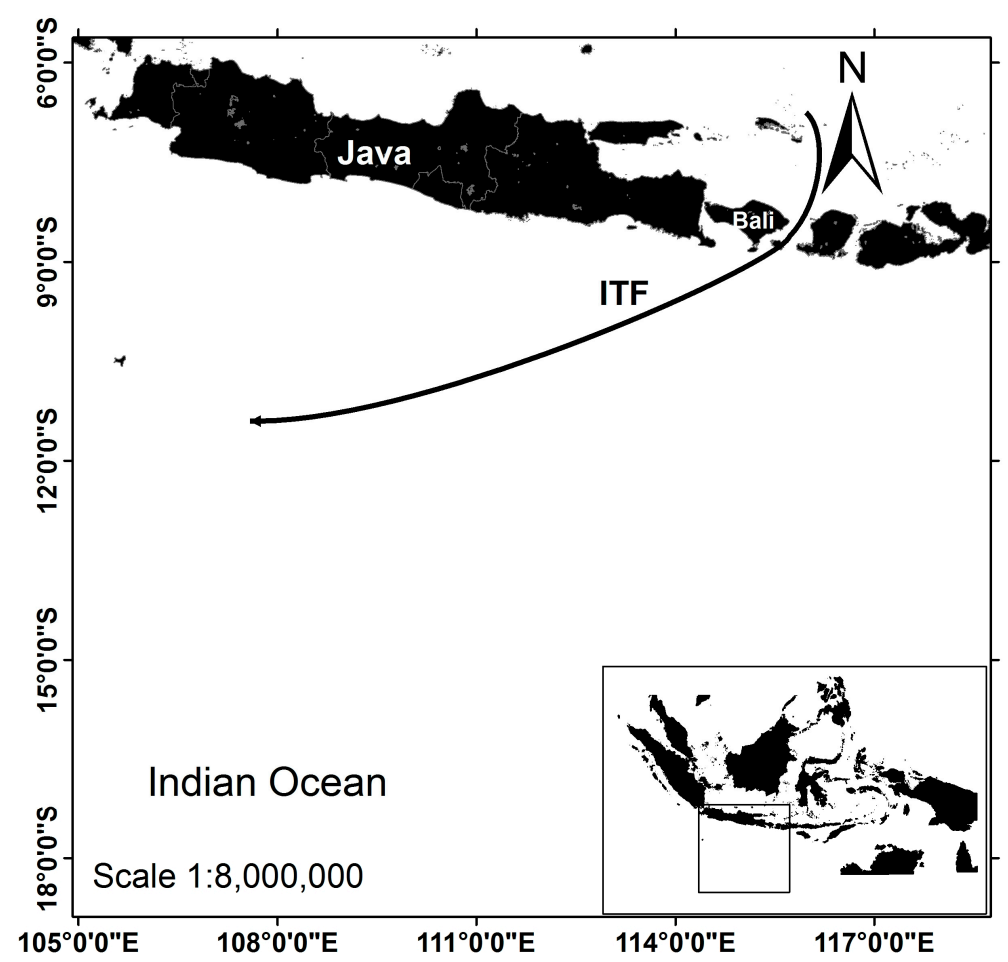

Figure 1. Study area.

It has a tropical monsoon type of climate, as a result of the Asia-Australian monsoon wind systems, which alter the wind direction in line with the seasons. The prevailing southeast monsoon affords upwelling along the coast off Sumatra, Java, and Bali between July and September, [20]. These conditions are adverse during the northwest monsoon (i.e., November to April; [10]). Moreover, the southern waters off Java-Bali are also influenced by ITF variability [35]. Physically, the study area and the surroundings have some complex dynamic currents and wave systems [35]. The range value of SST depends on the seasonal monsoon [36]. The surface layer of the tropical ocean is warm and the annual variation of temperature is normally small [36]. In addition, the range of SSC is inversely proportional with SST. Every year, the higher concentrations of SSC occur in June to September and lower concentrations occur in December, January, and February $[37,38]$. These conditions directly affect the amount of fishing catches [21].

\subsection{Fisheries Data and Remotely Sensed Environmental Data}

We analyzed daily catch data and remotely sensed environmental data within the period of 2006-2010. Data sets for bigeye tuna catches were used to examine the link between the number of bigeye tuna and environmental data. The bigeye tuna catch data were retrieved from nineteen longline fishing logbooks provided by PT Perikanan Nusantara (i.e., an integrated company of the Indonesian government, at Benoa, Bali). Most of the fishing efforts were conducted by 100 gross tonnage vessels size. In addition, the data sets consisted of latitude, longitude, daily catch data of bigeye tuna, and operational days. All the data sets were digitized and compiled into a database organized on a monthly basis. We considered the number of bigeye tuna caught (BE) as daily catch data. Although most scientists have employed catch per unit effort (CPUE) as an index for fish abundance $[20,37,38]$, we employed number of bigeye tuna caught as an index of fish abundance due to in-situ data limitations and because its trends which follow almost the same pattern as the hook rate (i.e., hook rate can be inferred as CPUE) data, as shown in the Figure 2. Moreover, we assume that a fish catch was the number caught by one boat in one location. As such, it is proportional to fish density in one location. 


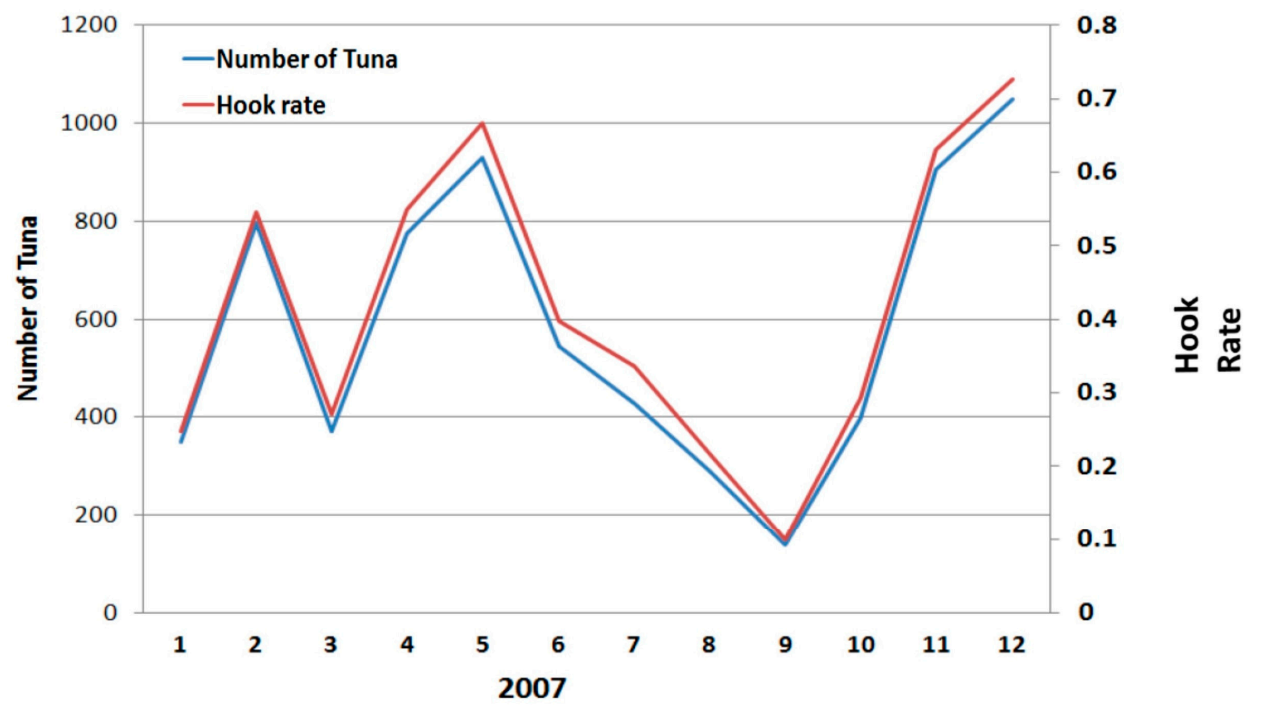

Figure 2. The relationship between number of tuna and hook rate [22].

SST, SSC, and SSHD were used as indices for remote sensing environmental data. Monthly SST $\left({ }^{\circ} \mathrm{C}\right)$ and SSC $\left(\mathrm{mg} / \mathrm{m}^{3}\right)$ were downloaded from Level 3 Standard Mapped Images (SMI) Aqua MODIS satellite data [39] with the spatial resolution of $4 \mathrm{~km}$. A correction of SSC was carried out to remove unexpected values (i.e., $<0$ and $>10 \mathrm{mg} / \mathrm{m}^{3}$ ) $[23,24]$. SSHD images were derived from the Aviso homepage by using the environmental data connector (EDC) with the spatial resolution of $17.8 \mathrm{~km}$. The images were then resampled to adjust the images corresponding to SST and SSC. The EDC is compatible with ArcGIS and can be downloaded freely from the National Oceanic and Atmospheric Administration (NOAA) website [40]. Moreover, the pixel values of the aforementioned environmental data were extracted with the location of the fishing activities by using the spatial analysis tool from ArcGIS software. The full matrix consisting of the number of bigeye tuna caught and environmental variables was the outcome from the extraction and it was employed for scatterplot smoothers analysis.

\subsection{Scatterplot Smoothers}

The scatterplot smoothers method was employed to analyze the link between number of bigeye tuna and environmental variables (i.e., SST, SSC, SSHD), as according to Tibshirani and Hastie (1986) [32]. In this method, each environmental variable as predictor variable was analyzed separately.

$$
E(Y \mid X)=s(X)
$$

where $Y$ represents the number of bigeye tuna, $X$ represents SST or SSC or SSHD, and $s$ is the smooth function of $X$. First, a logarithmic transformation was applied (i.e., $\log _{10}$ (number of bigeye tuna +1$)$ ). Transformation was conducted because the data type was integer and asymmetric. Moreover, before log-transformation, a factor of 1 was added to account for the null catches of the fisheries data. Then, to determine $s(X)$ from the data, any explanatory estimate of $E(Y \mid X=X)$ can be used. One class estimates are the local average estimates:

$$
\hat{s}\left(X_{\mathrm{i}}\right)=\operatorname{Ave}_{j \in N_{\mathrm{i}}}\left\{Y_{\mathrm{j}}\right\}
$$

where Ave represents the averaging operator (mean) of $Y_{\mathrm{j}}$ of $N_{\mathrm{i}}$ data. To estimate $N_{\mathrm{i}}$, the data is sorted by increasing $X$ value. This statement can be explained in Equation (3):

$$
N_{\mathrm{i}}=\left\{\min \left(w_{1}, 1\right),\left(w_{2}, 2\right), \ldots, \max \left(w_{50}, 50\right)\right\}
$$


where the total number of classes (knots) was determined (i.e., 50), $w$ is span/window/interval which has the same number of total points in each interval. In addition, the point in each interval was determined by the total number observations divided by the total number of classes. This is shown in Figure 3.

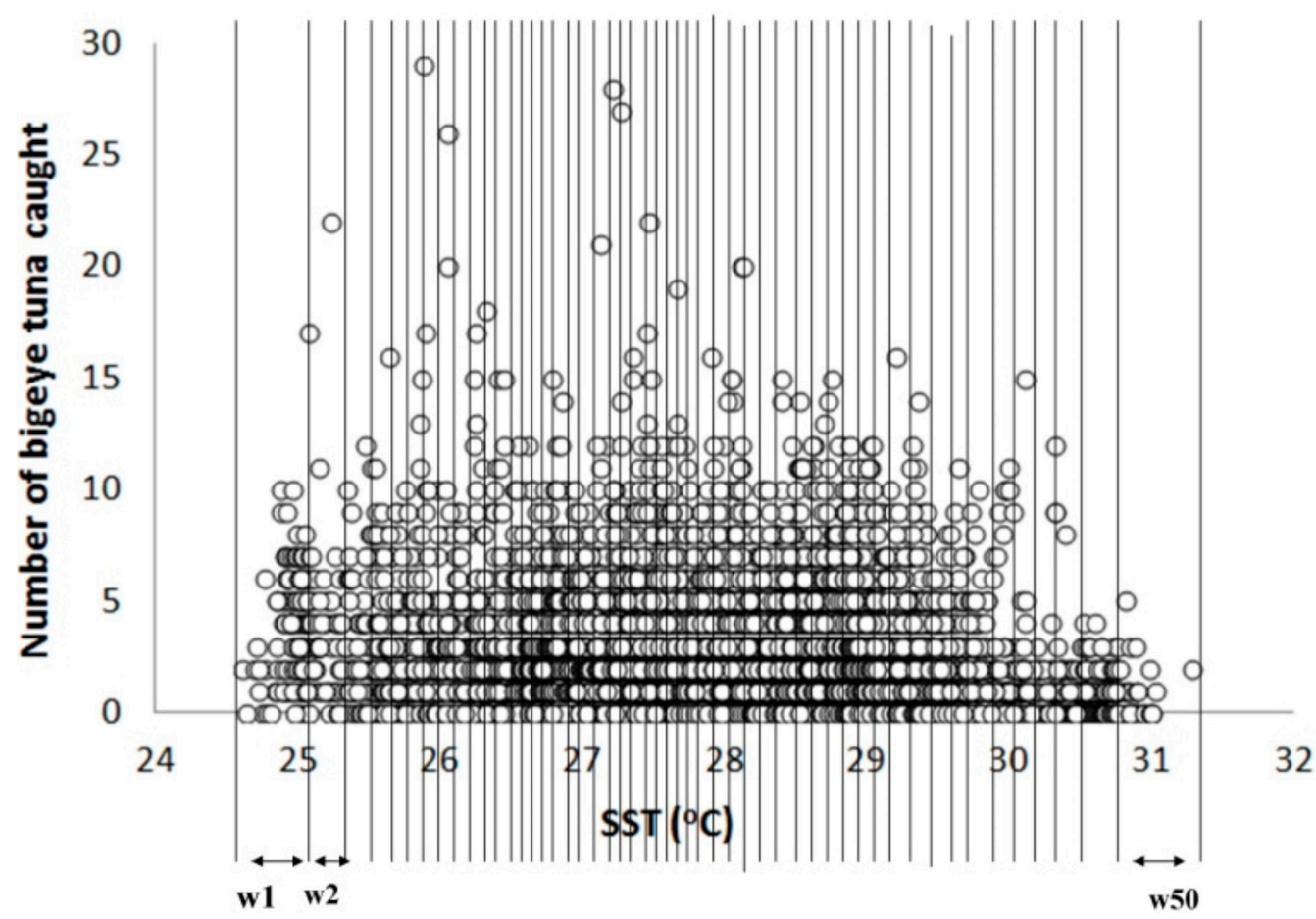

Figure 3. Data illustration. SST, sea surface temperature.

The smoothness of the estimate outcomes was controlled by the span, and it is determined according to the data distribution of each of the predictor variables. The Ave in Equation (2) of this study stands for polynomial estimates, as defined by:

$$
\begin{gathered}
\hat{s}\left(X_{\mathrm{i}}\right)=C_{1}+C_{2} X+C_{3} X^{2}+\ldots+C_{n+1} X^{n} \\
{\left[C_{\mathrm{k}}\right]=\left[\sum_{k=1}^{n} f_{\mathrm{i}}\left(X_{\mathrm{k}}\right) \times f_{\mathrm{j}}\left(X_{\mathrm{k}}\right)\right]_{n \times \mathrm{n}}^{-1}\left[\sum_{k=1}^{n} f_{\mathrm{j}}\left(X_{\mathrm{k}}\right) \times Y_{\mathrm{k}}\right]_{n \times 1}}
\end{gathered}
$$

where $f_{1}=1, f_{2}=X, f_{3}=X^{2}, f_{\mathrm{i}}=X^{n}, X$ is the average in each $w_{\mathrm{i}}$ span and $Y_{\mathrm{k}}$ is the average of $\log _{10}$ (number of bigeye tuna +1 ) in each $w_{\mathrm{i}}$ span, the bracket symbols indicate that all the calculations were determined by using a matrix. This model was evaluated by using $p_{\text {value }}$ (i.e., the probability that our data would be at least this inconsistent with the hypothesis) and the coefficient of determination $\left(R^{2}\right)$ was calculated to analyze the influence of predictor variables on the number of bigeye tuna, as defined below:

$$
R^{2}=1-\frac{\sum_{i=1}^{n}\left(Y_{\mathrm{k}}-\hat{s}\left(X_{\mathrm{i}}\right)\right)^{2}}{\sum_{i=1}^{n}\left(Y_{\mathrm{k}}-\bar{Y}\right)^{2}}
$$

where $\bar{Y}$ is the total average of the number of bigeye tuna. A high value of $R^{2}$ indicates that there is a strong relationship of both data. By applying scatter plot function, $\sigma^{2}$ (variance) of each span was almost the same, so that the trend can be determined. 


\subsection{Fisheries Data Classification}

Fisheries data classification is favorable for inferring the type of fish catch data and for determining the optimum value of environmental variables and also for being able to reduce the bias due to null catches [41]. The classification of fisheries data was divided into three groups based on the Quartile method [41], namely null catches (i.e., 0, positive catches (i.e., 1-3) and high catches (i.e., $\geq 4$ ). The number of four was calculated from the third quartile. The third quartile was obtained from 7750 observational data. The result of this analysis was the full matrix of null, positive, and high catches data and the adjusted values of SST, SSC, and SSHD. Table 1 shows a part of the full matrix. This result was applied to validate potential habitat for bigeye tuna.

Table 1. The full matrix of null, positive, and high catches data. BE, number of bigeye tuna; SST, sea surface temperature; SSC, sea surface chlorophyll; SSHD, sea surface height deviation.

\begin{tabular}{ccccccccc}
\hline Year & Month & Date & Latitude & Longitude & BE & SST & SSC & SSHD \\
\hline 2006 & 2 & 8 & -14.4167 & 111.6667 & 2 & 28.12 & 0.06 & -7.84 \\
2006 & 2 & 8 & -13.1667 & 113.0333 & 2 & 28.44 & 0.08 & -2.35 \\
2006 & 2 & 8 & -14.15 & 112.75 & 3 & 28.52 & 0.08 & -6.52 \\
2006 & 2 & 8 & -13.3333 & 114.6667 & 5 & 28.61 & 0.09 & -6.72 \\
2010 & $\mathrm{M}_{\mathrm{i}}$ & $\mathrm{D}_{\mathrm{i}}$ & Lat $_{\mathrm{i}}$ & Lon $_{\mathrm{i}}$ & $\mathrm{BE}_{\mathrm{i}}$ & SST $_{\mathrm{i}}$ & SSC $_{\mathrm{i}}$ & SSHD $_{\mathrm{i}}$ \\
\hline
\end{tabular}

\subsection{Generating the Optimum Range of Environmental Variables}

Preferred environmental conditions were obtained by considering the difference of predicted values of bigeye tuna (i.e., scatter plot smoothers) and the total average of bigeye tuna. If the estimated value of bigeye tuna was higher than average ones, it meant that the environmental variables range gave a positive effect for big eye tuna, as shown in Equations (7) and (8).

$$
\bar{Y}=\frac{1}{n} \sum_{i=1}^{n}\left(Y_{\mathrm{i}}\right)
$$

with the indicator functions

$$
\begin{gathered}
\hat{Y}>\bar{Y}(\text { Positive Effect }) \\
\hat{Y}<\bar{Y}(\text { Negative Effect })
\end{gathered}
$$

where $\bar{Y}$ is the average number of bigeye tuna, $n$ is the number of samples, and $\hat{Y}$ is the estimated value of big eye tuna in each environmental variable from scatter smoothers calculations. Furthermore, the positive effect was considered to be the optimum range and this result was then used to generate simple predicted distribution map.

\subsection{Generating a Simple Predicted Distribution Map}

Potential habitat was assessed to determine the spatial distribution of preferred ocean properties for bigeye tuna. The raster calculator function in ArcGIS 10.3 was applied to compute potential habitat. The preferred ocean properties were compiled based on scatter plot smoothers and scored by "an additive priority function $P$ ", as displayed in Equation (9):

$$
P=\left(0.62 \times X_{1}\right)+\left(0.65 \times X_{2}\right)+\left(0.45 \times X_{3}\right)
$$

where $P$ is potential habitat, $X_{1}$ is SST, $X_{2}$ is SSC, and $X_{3}$ is SSHD (Equations (10)-(12)):

$$
X_{1}=\left\{\begin{array}{c}
1, \text { optimum range of SST } \\
0, \text { non }- \text { optimum range of SST }
\end{array}\right.
$$




$$
\begin{gathered}
X_{2}=\left\{\begin{array}{c}
1, \text { optimum range of SSC } \\
0, \text { non }- \text { optimum range of SSC }
\end{array}\right. \\
X_{3}=\left\{\begin{array}{c}
1, \text { optimum range of SSHD } \\
0, \text { non }- \text { optimum range of SSHD }
\end{array}\right.
\end{gathered}
$$

The optimum value of each variable was calculated according to scatter plot smoothers results (Sections 2.3 and 2.5). In addition, the constant numbers for SST, SSC, and SSHD are the weight values which were determined based on the PCA analysis. The PCA was computed by the following equation. Given a data matrix with three variables and 7750 samples, the data were first centered on the means of each variable by creating a covariance matrix (Equation (13)). Then, Eigenvalues and corresponding Eigen vectors were calculated, as shown in Equations (14) and (15). Finally, we computed the loading factor (i.e., Equation (16)), which has the same meaning with weight/score for each of the covariates.

$$
\begin{gathered}
A=\frac{1}{n} \sum(X-\mu)(X-\mu)^{T} \\
(A-\lambda I)=0 \\
{[A-\lambda][x]=[0]}
\end{gathered}
$$

The above equation symbols are explained as follows, $A$ is the covariance matrix, $X$ represents the predictor variables, $n$ is the sample number, $T$ is transpose, $\mu$ is the mean of each predictor variables, $\lambda$ is the eigenvalue, $I$ is the identity matrix, $x$ is the corresponding eigenvector of $X$. The PCA was computed in $\mathrm{R}$ version 3.03, using PCA function of the princomp package.

By conducting the PCA analysis, the weight value was calculated by combining the eigenvalue and corresponding eigenvector for each of the variables, as explained in Equation (16) [42] and Table 2.

$$
\text { Weight }=x \times \sqrt{\lambda}
$$

Table 2. Weighting of each of the environmental variables.

\begin{tabular}{cccc}
\hline Environmental Variables & $\boldsymbol{x}$ & $\boldsymbol{\lambda}$ & Weight \\
\hline SST & 0.45 & 1.87 & 0.62 \\
SSC & 0.48 & 1.87 & 0.65 \\
SSHD & 0.33 & 1.87 & 0.45 \\
\hline
\end{tabular}

In addition, the PCA combination explained $62.5 \%$ variance and the rest was explained by the other factors. The variance explained was obtained by the eigenvalue proportions (i.e., eigenvalue first component divided by total eigenvalue).

\section{Results and Discussion}

\subsection{Scatter Smoothers}

The relationship between the average, variance $\left(\sigma^{2}\right)$, maximum value of bigeye tuna, and SST is shown in Figure 4. The statistical parameter of the $Y$ axis is the conversion of the number of bigeye tuna into $\log (\mathrm{BE}+1)$, where $\mathrm{BE}$ indicates the number of bigeye tuna. The average and variance values were obtained by the scatterplot smoothers method (i.e., by averaging the value of $\mathrm{BE}$ in each interval/span) in this figure. The solid line represents the average BE in each span $w$, the dashed line represents $\sigma^{2}$, and the dotted dashed line represents the maximum value in each span. By conducting scatter smoothers, the trend of bigeye tuna caught is reliable because the variance value is almost constant. As a result, bigeye tuna environmental preference can be roughly distinguished. According to Figure 4, 
bigeye tuna were present in the area when the SST was from 24.6 to $30.8^{\circ} \mathrm{C}$. Moreover, the number of bigeye tuna tended to decrease when SST increased, especially when SST was higher than $29.4^{\circ} \mathrm{C}$.

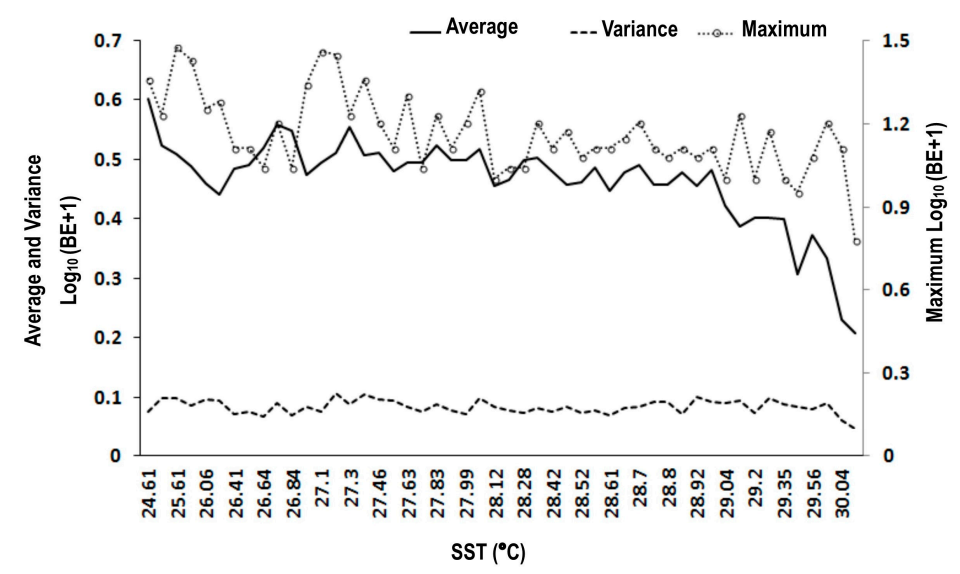

Figure 4. Number of bigeye tuna in relation to SST during 2006-2010.

Figure 5 describes the relationship between SSC and the number of bigeye tuna. This figure indicates that bigeye tuna were present in the area when the SSC was from $0.02-0.34 \mathrm{mg} / \mathrm{m}^{3}$. Moreover, bigeye tuna tended to increase as the SSC increased to $0.151 \mathrm{mg} / \mathrm{m}^{3}$, but with a reading higher than this, the number of bigeye tuna tended to decrease.

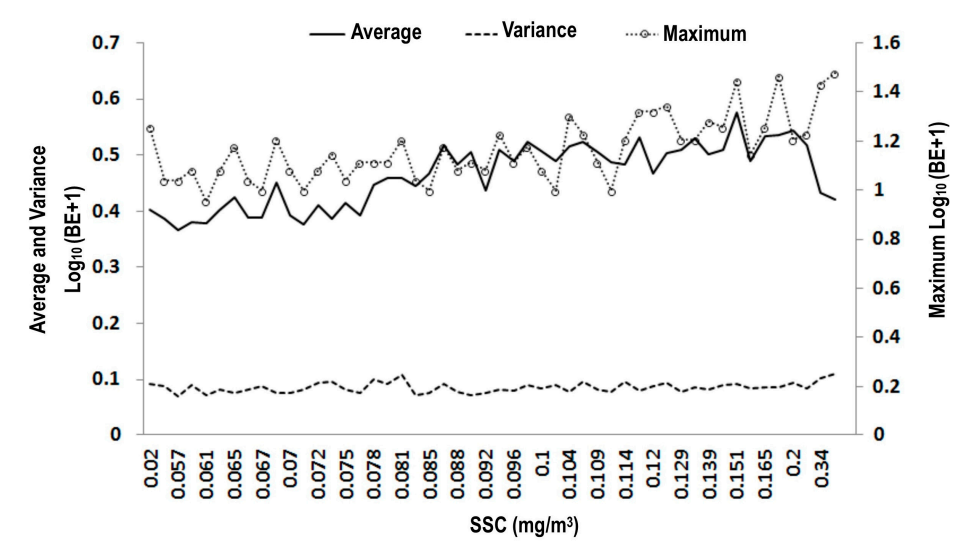

Figure 5. Number of bigeye tuna in relation to SSC during 2006-2010.

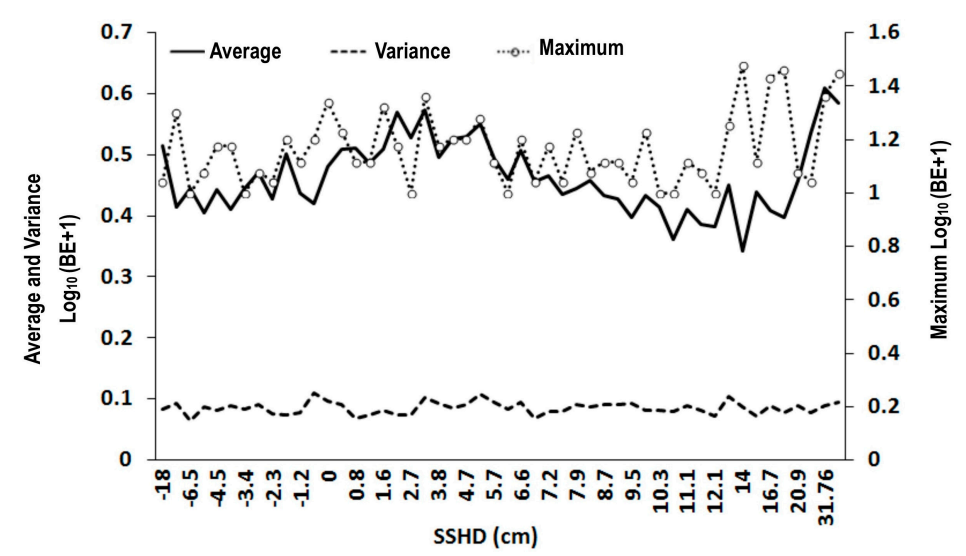

Figure 6. Number of bigeye tuna in relation to SSHD during 2006-2010. 
Figure 6 shows the relationship among the number of bigeye tuna and SSHD. Bigeye tuna were found in the area when the SSHD ranged from -18.46 to $31.76 \mathrm{~cm}$. In addition, the variance was also constant, as shown by the dashed line, with the average number of bigeye tuna fluctuating as shown by the solid line, and the maximum number of bigeye tuna was higher when it reached the extreme positive of SSHD.

\subsection{Relationship between Environmental Factors and Bigeye Tuna Caught}

The relationship between environmental factors and bigeye tuna caught was calculated by Equations (4)-(6). Equations (4) and (5) were used to evaluate the trend and Equation (6) was used to determine the relationship of strength between the variables. The relationship between environmental factors and bigeye tuna caught was evaluated separately. Moreover, the optimum value of each factor was computed by Equations (7) and (8). This was indicated with the horizontal dashed line in Figures 7-9.

Figure 7 shows the trend and relationship between the average number of bigeye tuna caught and SST. According to Figure 7, SST has a strong relationship with bigeye tuna, which is indicated by the coefficient of determination $\left(R^{2}\right)$ of 0.85 . In addition, the correlation trend between the number of bigeye tuna and SST was negative, which means that bigeye tuna numbers tend to decrease when SST increased. In other words, bigeye tuna prefer to remain in the low SST around the study area. This result displays the same trends as those observed with the GAM analysis in the same study area [21,25]. The optimum value can be inferred by determining the threshold (i.e., average number of bigeye tuna). If the estimated value was higher than the threshold, it means SST resulted in a positive impact for bigeye tuna. According to Figure 7, the positive impact of SST occurred at less than $28.5^{\circ} \mathrm{C}$.

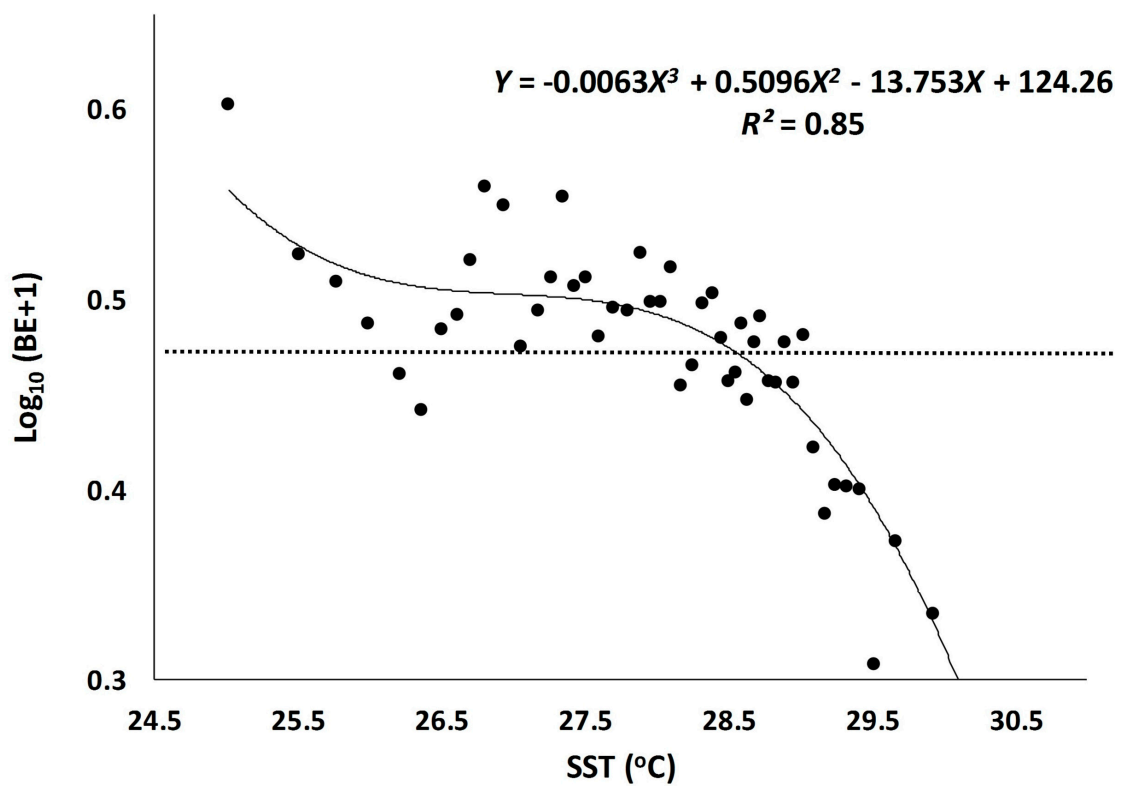

Figure 7. Average number of bigeye tuna SST.

Figure 8 shows the relationship between the average number of bigeye tuna caught and SSC. It shows that SSC has a strong relationship with bigeye tuna, which is indicated by the $R^{2}$ of 0.78 . Moreover, SSC has a positive impact on bigeye tuna when the SSC concentration is between 0.09 to $0.25 \mathrm{mg} / \mathrm{m}^{3}$ and a negative impact on bigeye tuna when the SSC is less than $0.09 \mathrm{mg} / \mathrm{m}^{3}$ and bigger than $0.25 \mathrm{mg} / \mathrm{m}^{3}$. 


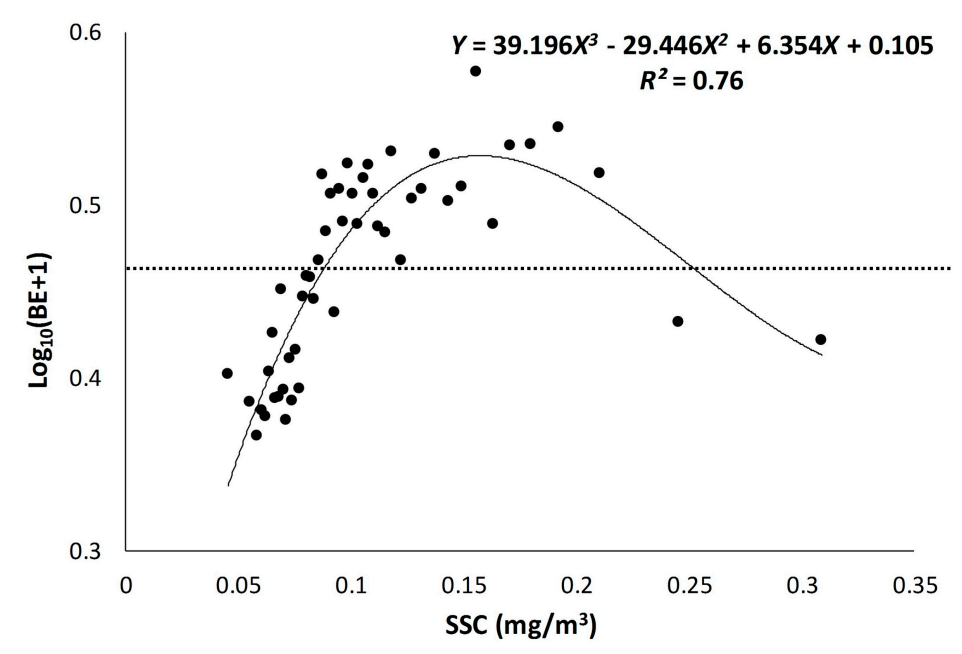

Figure 8. Average number of bigeye tuna in relation to SSC.

Figure 9 shows the relationship between the average number of bigeye tuna and SSHD. This figure shows that SSHD had a strong relationship with bigeye tuna with a $R^{2}$ of 0.72 . From this figure, the number of bigeye tuna was fluctuating. Moreover, it was high when SSHD was in the extreme negative values, low positive values, and extreme positive values. However, on both sides of the extreme negative and extreme positive values, the standard error of SSHD was also high (i.e., it is related with a wide span size in the extreme values), so that the optimum value of SSHD was between -3 and $7 \mathrm{~cm}$.

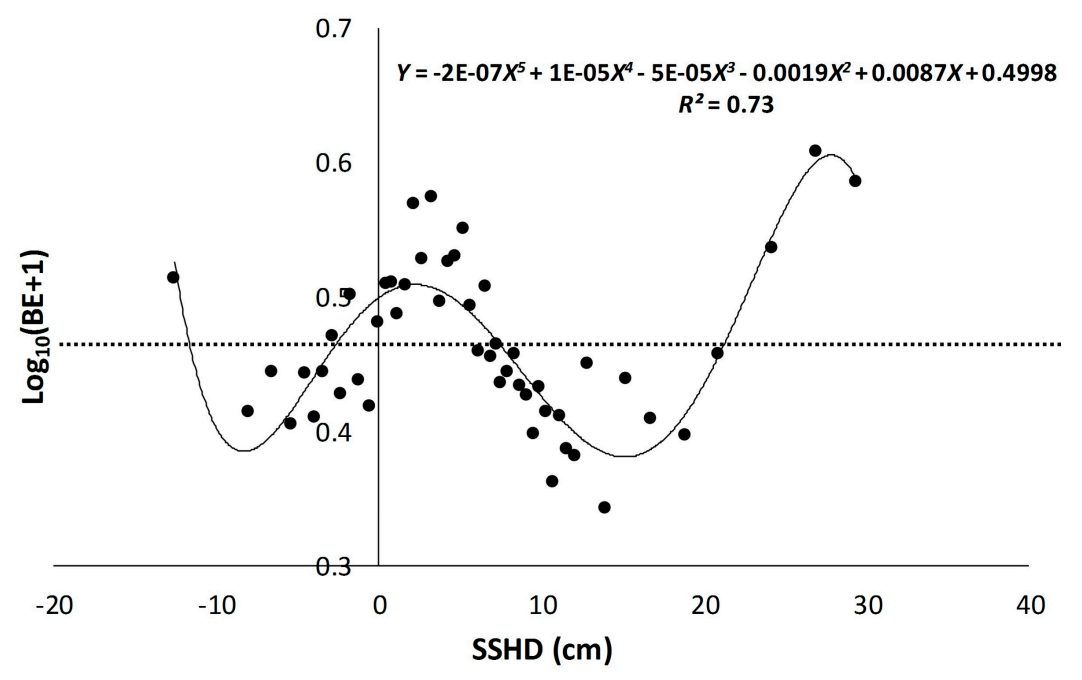

Figure 9. Average number of bigeye tuna in relation to SSHD.

The results of Figures 8-10 were summarized in Table 2.

Table 3. Regression analysis results.

\begin{tabular}{ccc}
\hline Model & $\boldsymbol{p}$-Value & $\boldsymbol{R}^{\mathbf{2}}$ \\
\hline SST & $3.7 \times 10^{-19}$ & 0.85 \\
SSC & $3.12 \times 10^{-14}$ & 0.78 \\
SSHD & $1.53 \times 10^{-11}$ & 0.73 \\
\hline
\end{tabular}


According to Table 3, three environmental variables were highly significant to the number of bigeye tuna, as shown by the low $p$-values $(p$-value $<0.01)$. Furthermore, the aforementioned variables influenced the number of bigeye tuna caught with the range of $R^{2}$ equal to $64 \%$ to $82 \%$, thus indicating that there was a strong relationship.

Scatterplot smoothers can estimate how important the impacts of different environmental variables are to the number of bigeye tuna. Those preferred environmental conditions of bigeye tuna were then plotted into a simple predicted distribution map, as shown in Figure 10.
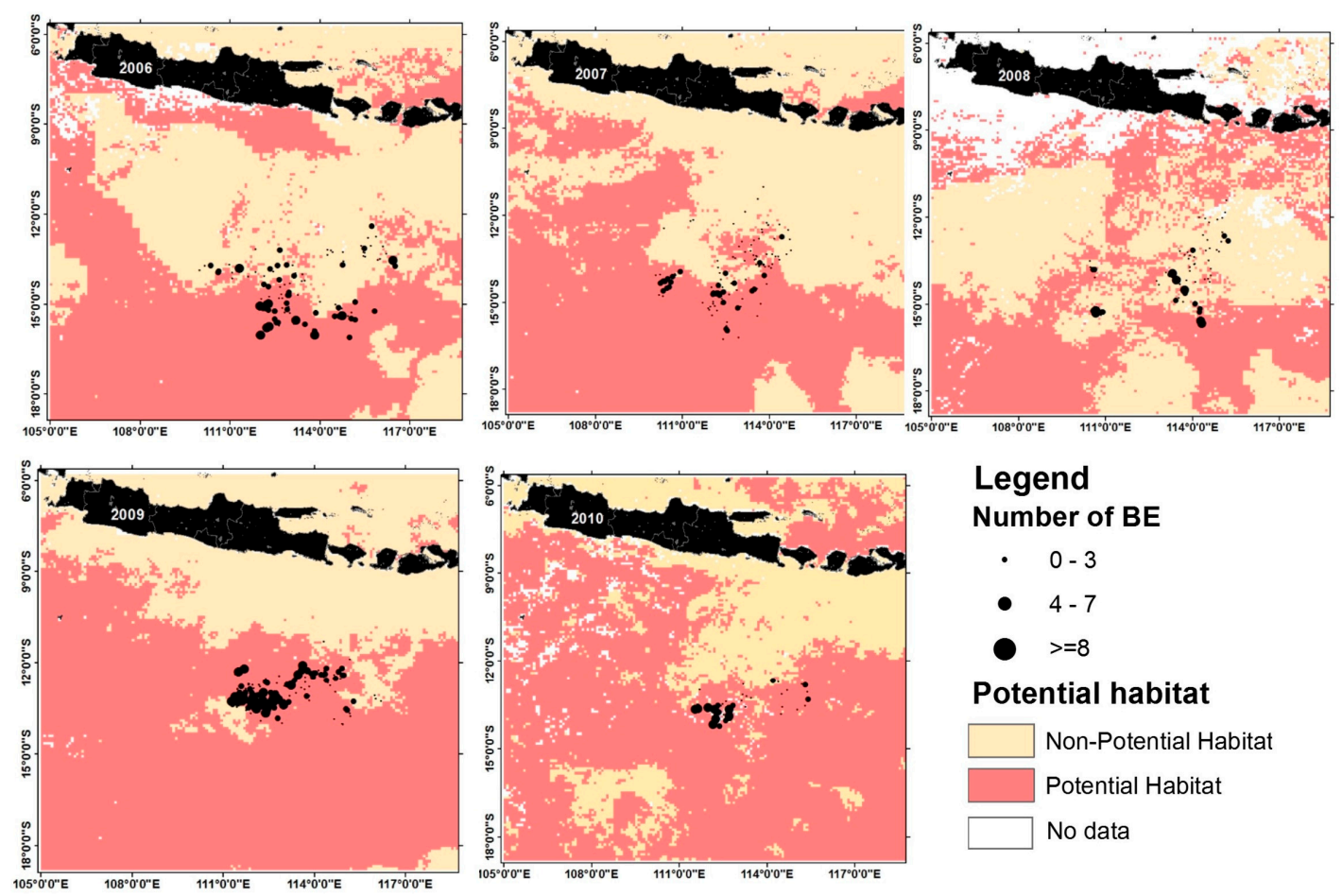

Figure 10. Spatial distribution of longline fisheries in July from 2006 to 2010 (black dots) overlaid with simple prediction map generated from combination of SST, SSC, and SSHD. BE, bigeye tuna.

Figure 10 displays the preferred location of bigeye tuna in July from 2006 to 2010. Pink colored areas indicate potential habitat, light brown colored areas indicate non-potential habitat, and white colored areas indicate missing value/no data. The maps were then overlaid with the number of BE which are indicated with black dot symbols. July was selected for the predicted map due to the highest frequency of high catches data in the study area. It occurred due to the annual coastal upwelling which typically reaches its peak in July [43]. Furthermore, the eddy current system encourages nutrients and chlorophyll from the coast towards the open sea [43]. These nutrients and the chlorophyll represent a major feature of primary production that lasts long enough to sustain zooplankton production and upper trophic levels [44]. In addition, the potential habitat was mostly found in the western and southern part of the study area. This spatial distribution result also had the same agreement with results the GAM method [25] and the frontal zone in the study area [4].

\subsection{Model Validation and Potential Habitat Prediction}

For validation purposes, 651 samples were employed based on the highest catch period (i.e., July) from 2006-2010. The quantitative method was conducted for validation, which based on the contingency table shown in Table 4. In Table 4, the tuna catches column, "yes" was defined as high catches (i.e., $\mathrm{BE} \geq 4$ ) and "no" was defined as zero and positive catches $(\mathrm{BE} \leq 3)$. To calculate the accuracy percentage, POD (Probability of Detection) and FAR (False Alarm Ratio) measurements were conducted. POD describes how good the model estimates are in detecting the occurrence of high 
catches and FAR measures the fraction of diagnosed events that turned out to be wrong. The POD and FAR were calculated by following equations (Equations (17) and (18), respectively):

$$
\begin{aligned}
& \mathrm{POD}=\frac{A}{A+C} \\
& \mathrm{FAR}=\frac{B}{A+B}
\end{aligned}
$$

where $A$ refers to correctly estimated, $B$ refers to areas where potential habitat was predicted, but where high catches did not occur, $C$ represents areas where non-potential habitat was predicted, but high catches occurred, and $D$ represents correctly predicted areas of non-potential habitat.

Table 4. Contingency table.

\begin{tabular}{cccc}
\hline \multirow{2}{*}{ Fisheries In-Situ Data } & \multicolumn{2}{c}{ Potential Habitat } \\
\cline { 3 - 4 } & & Yes & No \\
\hline Tuna & Yes & $210(A)$ & $51(C)$ \\
catches & No & $262(B)$ & $128(D)$ \\
\hline
\end{tabular}

Based on Table 4, POD and FAR values were $80.5 \%$ and $55.5 \%$, respectively. This means that $80.5 \%$ of the model areas were correctly detected and $55.5 \%$ of the model predictions turned out to be wrong. Even though the result was not as high as expected, we consider that the potential habitat map can estimate the bigeye tuna distribution.

\subsection{Relationship between Ocean Dynamics and Preferred Habitat for Bigeye Tuna}

Combining observations of ocean dynamics from satellite and in-situ observations related to abundant fisheries is necessary because they are complimentary types of data. In this study, we combined remote sensing data and catch data of bigeye tuna in order to examine the relevance between the number of bigeye tuna and environmental variables. The availability of bigeye tuna catch data from one of the biggest tuna fishing industries in Indonesia greatly helped in providing the fish catch data in the study area According to the distribution of fishing activity, the fishing efforts of the tuna long lines were distributed within $10^{\circ} \mathrm{S}-18^{\circ} \mathrm{S}$ and $110^{\circ} \mathrm{E}-118^{\circ} \mathrm{E}$, and this had not changed significantly for five years. Hence, the change of environmental variables is important for evaluating bigeye tuna distributions within the study area.

Bigeye tuna catch rates differed along with time and environmental factor variations [25]. Like other pelagic species, bigeye tuna have their preferred living environments. As such, there should be a correlation between bigeye tuna catch with the ocean properties, such as SST, SSC, and SSHD. However, fishing activity of bigeye tuna is only concentrated in this certain area which caused the variance in the number of bigeye tuna to be irregular. In order to evaluate the relationship between bigeye tuna and environmental variables, variance of bigeye tuna has to be constant. Hence, a scatterplot smoother was conducted. To create constant variance, Equations (1)-(3) were applied and the results were shown in Figures 4-7. According to those figures, the variance in the number of bigeye tuna was relative to each environmental parameter and was constant (i.e., it was shown as a dashed line). As a result, the link between bigeye tuna and the ocean properties can be evaluated. Figures 8-10 explain the relation among those environmental variables. Those figures stated that bigeye tuna have a high correlation with environmental variables and tend to stay in areas with low SST, low SSC, and in low positive values of SSHD and extreme SSHD. These conditions are related to bigeye tuna behavior.

Bigeye tuna prefer to stay in low SST to prevent overheating [6], thus they would need to curtail heat retention to avoid thermal limits of activity and distribution [26]. This condition mostly occurs in the tropical waters which have almost the same SST. For that reason, in Figure 7, SST has 
a negative correlation with bigeye tuna. The other environmental variable which influenced bigeye tuna distribution was SSC. Bigeye tuna rely on their visual ability to forage for their prey, so water clarity represents a crucial factor [5]. They appear to stay in clear water to increase the efficiency of prey foraging. Clear water means poor availability of nutrients, which can be reworded as low SSC concentration. Hence, most of the fishing activities were found in the low SSC. Even though fishery data is not free from bias, it represents a low-cost source of data for fish distribution which available to scientists [27]. SSHD also influenced bigeye tuna behavior, because bigeye tuna migration is influenced by the thermocline layer and it can be measured by calculating SSHD [21]. According to Syamsuddin [45], "extreme negative SSHD gave the positive effect to bigeye tuna" because it made the thermocline layer closer to the surface. In this study, extreme negative SSHD resulted in a positive effect in regards to the number of bigeye tuna (Figure 10), but it had high standard error. This is probably because extreme negative SSHD can be found only during an El Niño event. In addition, low positive SSHD resulted in the lowest standard error of SSHD and resulted in a positive effect in regards to the number of bigeye tuna in the study area. Bigeye tuna are characterized as opportunistic feeders, and their forage is usually composed of a diverse variety of organisms such as crustaceans, fish, gelatinous creatures, and squids [5], which can be found in the deep water of $250 \mathrm{~m}$ to more than $500 \mathrm{~m}$. In addition, bigeye tuna spend the daytime in the deep water from 250 to $600 \mathrm{~m} \mathrm{[4]} \mathrm{and} \mathrm{the}$ nighttime in the surface water [4]. The optimum range of environmental variables for bigeye tuna was calculated using threshold line for comparable values with estimated ones. The result showed that the highest number of bigeye tuna corresponded to the area of about less than $28.5^{\circ} \mathrm{C}$ of SST, 0.09 to $0.23 \mathrm{mg} / \mathrm{m}^{3}$ of SSC, and -3 to $7 \mathrm{~cm}$ of SSHD (and the extreme value) (Figures 7-9). Thus, these areas were designated as potential habitat for bigeye tuna (Figure 10). It is interesting to reveal that these biophysically essential areas can be projected over a map to recognize their spatial pattern. Furthermore, all environmental variables gave a strong correlation with the number of bigeye tuna. Therefore, these could be noted as acceptable indices of environmental properties that could be used to find the highest probability areas of big eye tuna presence. Overall, the SST, SSC, and SSHD ranges in the study area were relatively small compared with the conditions encountered in subtropical areas, and this makes it difficult to understand the relationship of these data and bigeye tuna fisheries data by using statistical analysis. In addition, our model explained $80.5 \%$ of the POD accuracy assessment. Environmental variables are necessary in projecting the bigeye tuna habitat, but are presumably not the only factors which drive the preferred habitat for this species.

\section{Conclusions}

The environmental preference of bigeye tuna in the study area was determined by using a remote sensing satellite data approach. Daily fish catch data and monthly satellite data of SST, SSC, and SSHD within the period of 2006-2010 were considered. To characterize the preferred habitat for bigeye tuna, the scatterplot smoothers method and GIS were utilized. The results showed that SST, SSC, and SSHD had a high correlation with the abundance of bigeye tuna. Therefore, all of these environmental factors could be noted as acceptable indices to study the bigeye tuna's preferred habitat. The spatial patterns of bigeye tuna preference have a typical characteristic of low SST, low SSC, and low positive SSHD, as well as areas with extreme SSHD. In future research, more predictor variables and longer time periods are necessary to improve our understanding of the relationship between environmental variables and bigeye tuna fisheries.

Acknowledgments: We would like to thank Perikanan Nusantara Ltd., Benoa, Bali, Indonesia for providing fisheries data. We thank to Kementrian Pendidikan dan Kebudayaan (Ministry of Education of Indonesia), Lembaga Pengelola Dana Pendidikan (Indonesia Endowment Fund of Ministry of Finance), and JAXA (Japan Aerospace Exploration Agency) for financial support. We also gratefully acknowledge NASA for the ocean color AQUA-MODIS SST and chlorophyll-a data that were downloaded from ocean-color homepage and the use of altimetry data for SSHD data sets downloaded from the AVISO homepage.

Author Contributions: Martiwi Diah Setiawati designed and performed the experiment, analyzed the data, and wrote the paper. Tasuku Tanaka is the second author; he also designed the experiment and analyzed the data. 
Conflicts of Interest: The authors declare no conflict of interest.

\section{References}

1. Pillai, N.G.K.; Satheeshkumar, P. Biology, fishery, conservation and management of Indian Ocean tuna fisheries. Ocean Sci. J. 2012, 47, 411-433. [CrossRef]

2. ISSF. ISSF Stock Status Ratings-2012-Status of the World Fisheries for Tuna. Available online: https:/ / troubledwatersfilm.files.wordpress.com/2015/01/issf-2012-status-of-the-world-fisheries-fortuna.pdf (accessed on 5 December 2015).

3. Wujdi, A.; Rochman, F.; Jatmiko, I. Length Distribution and Sex Ratio to Investigate Spawn Eligibility of Bigeye Tuna (Thunnus obesus Lowe, 1839) in the Indian Ocean (in Indonesian). Widyariset 2016, 2, 67-76. [CrossRef]

4. Howell, E.A.; Hawn, D.R.; Polovina, J.J. Spatiotemporal variability in Bigeye tuna (Thunnus obesus) dive behaviour in the Central North Pacific Ocean. Prog. Oceanogr. 2010, 86, 81-93. [CrossRef]

5. Sund, P.N.; Blackburn, M.; William, F. Tunas and their environment in the Pacific Ocean: A review. Oceanogr. Mar. Biol. Ann. Rev. 1981, 19, 443-512.

6. Brill, R.W.; Bigelow, K.A.; Musyl, M.K.; Fritsches, K.A.; Warrant, E.J. Bigeye tuna (Thunnus obesus) behavior and physiology and their relevance to stock assessments and fishery biology. Col. Vol. Sci. Pap. ICCAT 2005, 57, 142-161.

7. Mohri, M.; Nishida, T. Distribution of bigeye tuna (Thunnus obesus) and its relationship to the environmental conditions in Indian Ocean based on the Japanese longline fisheries information. IOTC Proc. 1999, 2, 221-230.

8. Pranowo, W.S.; Tisiana, A.; Nugraha, B.; Novianto, D.; Muawanah, U. Ocean-Climate Interaction of Eastern Indian Ocean for Tuna. Available online: http://wwa.iotc.org/sites/default/files/documents/2014/11/ IOTC-2014-WPTT16-23_-_Ocean_climate_interaction.pdf (accessed on 5 December 2015).

9. Pranowo, W. Fenomena di Laut Selatan Jawa Tersebut Kami Beri Nama "RATU”. Indones. Marit. Mag. 2014, $44,44-45$.

10. Susanto, R.D.; MooreII, T.S.; Marra, J. Ocean color variability in the Indonesian Seas during the SeaWiFS era. Geochem. J. 2006, 7. [CrossRef]

11. Sachoemar, S.; Yanagi, T. Temporal and Spatial Variability of Sea Surface Temperature within Indonesian Regions Revealed by Satellite Data. Rep. Res. Inst. Appl. Mech. Kyushu Univ. 2013, 145, 37-41.

12. Zainuddin, M.; Kiyofuji, H.; Saitoh, K.; Saitoh, S.-I. Using multi-sensor satellite remote sensing and catch data to detect ocean hot spots for albacore (Thunnus alalunga) in the northwestern North Pacific. Deep Sea Res. Part II Top. Stud. Oceanogr. 2006, 53, 419-431. [CrossRef]

13. Sprintall, J.; Wijffels, S.E.; Molcard, R.; Jaya, I. Direct Estimates of the Indonesian Throughflow Entering the Indian Ocean: 2004-2006. J. Geophys. Res. 2009, 114. [CrossRef]

14. Gordon, A.L. Oceanography of the Indonesian Seas and Their Throughflow. Oceanography 2005, 18, $14-27$. [CrossRef]

15. Nishikawa, Y.; Honma, M.; Ueyanagi, S.; Kikawa, S. Average Distribution of Larvae of Oceanic Species of Scombroid Fishes, 1956-1981; Far Seas Fisheries Research Laboratory: Simizu, Japan, 1985; p. 99.

16. Nishida, T.; Mohri, M.; Itoh, K.; Nakagome, J. Study of Bathymetry Effects on the Nominal Hooking Rates of Yellowfin Tuna (Thunnus albacares) and Bigeye Tuna (Thunnus obesus) Exploited by the Japanese Tuna Longline Fisheries in the Indian Ocean. Available online: http:/ / citeseerx.ist.psu.edu/viewdoc/similar? doi=10.1.1.467.4954\&type $=$ ab (accessed on 6 November 2016).

17. Chassot, E.; Bonhommeau, S.; Reygondeau, G.; Nieto, K.; Polovina, J.J.; Huret, M.; Dulvy, N.K.; Demarcq, H. Satellite remote sensing for an ecosystem approach to fisheries management. ICES J. Mar. Sci. 2011, 68, 651-666. [CrossRef]

18. Klemas, V. Fisheries applications of remote sensing: An overview. Fish. Res. 2013, 148, 124-136. [CrossRef]

19. Polovina, J.J.; Howell, E.A. Ecosystem indicators derived from satellite remotely sensed oceanographic data for the North Pacific. ICES J. Mar. Sci. 2011, 62, 319-327. [CrossRef]

20. Du, Y.; Qu, T.; Meyers, G.; Masumoto, Y.; Sasaki, H. Seasonal heat budget in the mixed layer of the southeastern tropical Indian Ocean in a high-resolution ocean general circulation model. J. Geophys. Res. 2005, 110. [CrossRef] 
21. Syamsuddin, M.L.; Saitoh, S.I.; Hirawake, T.; Bachri, S.; Harto, A.B. Effects of El Niño-Southern Oscillation events on catches of Bigeye Tuna (Thunnus obesus) in the eastern Indian Ocean of Java. Fish. Bull. 2013, 111, 175-188. [CrossRef]

22. Kasma, E.; Osawa, T.; Adnyana, I.W.S. Estimation of primary productivity for tuna in Indian Ocean. Ecotrophic J. Environ. Sci. 2010, 4, 86-91.

23. Maritorena, S.; D'Andon, O.H.F.; Mangin, A.; Siegel, D.A. Merged satellite ocean color data products using a bio-optical model: Characteristics, benefits and issues. Remote Sens. Environ. 2010, 114, 1791-1804. [CrossRef]

24. Abbot, M.R.; Letelier, R.M. Chlorophyll Fluorescence (MODIS Product Number 20). Available online: http:/ / citeseerx.ist.psu.edu/viewdoc/summary?doi=10.1.1.551.9575 (accessed on 3 June 2016).

25. Setiawati, M.D.; Sambah, A.B.; Miura, F.; Tanaka, T.; Ass-syakur, A.R. Characterization of bigeye tuna habitat in the Southern Waters off Java-Bali using remote sensing data. Adv. Space Res. 2015, 55, 732-746. [CrossRef]

26. Neill, W.H.; Chang, R.K.C.; Dizon, A.E. Magnitude and ecological implications of thermal inertia in skipjack tuna Katsuwonus pelamis (Linneaus). Environ. Biol. Fish. 1976, 1, 61-80. [CrossRef]

27. Mugo, R.; Saitoh, S.I.; Nihara, A.; Kuroyama, T. Habitat characteristics of skipjack tuna (Katsuwonus pelamis) in the Western North Pasific. Fish. Oceanogr. 2010, 19, 382-396. [CrossRef]

28. Bailey, C.; Dwiponggo, A.; Marahudin, F. Indonesia Marine Capture Fisheries (1987). Available online: http:/ / pubs.iclarm.net/libinfo/Pdf/Pub\%20SR76\%2010.pdf (accessed on 3 June 2016).

29. Osawa, T.; Julimantoro, S. Study of Fishery Ground around Indonesia Archipelago Using Remote Sensing Data. In Adaptation and Mitigation Strategies for Climate Change; Springer: Tokyo, Japan, 2010; pp. 57-69.

30. Laurs, R.M.; Fiedler, P.C.; Montgomery, D.R. Albacore tuna catch distributions relative to environmental features observed from satellites. Deep Sea Res. Part A Oceanogr. Res. Pap. 1984, 31, 1085-1099. [CrossRef]

31. Zainuddin, M.; Saitoh, K.; Saitoh, S.I. Albacore (Thunnus alalunga) fishing ground in relation to oceanographic condition in the Western North Pacific Ocean using remotely sensed satellite data. Fish. Oceanogr. 2008, 17, 61-73. [CrossRef]

32. Hastie, T.J.; Tibshirani, R.J. Generalized Additive Models; CRC Press: New York, NY, USA, 1990.

33. Muhling, B.A.; Reglero, P.; Ciannelli, L.; Alvarez-Berastegui, D.; Alemany, F.; Lamkin, J.T.; Roffer, M.A. Comparison between environmental characteristics of larval bluefin tuna Thunnus thynnus habitat in the Gulf of Mexico and Western Mediterranean Sea. Mar. Ecol. Prog. Ser. 2013, 486, 257-276. [CrossRef]

34. Reygondeau, G.; Maury, O.; Beugrand, G.; Fromentin, J.M.; Fonteneau, A.; Curry, P. Biogeography of tuna and billfish communities. J. Biogeogr. 2012, 39, 114-129. [CrossRef]

35. Feng, M.; McPhaden, M.J.; Xie, S.P.; Hafner, J. La Niña forces unprecedented Leeuwin Current warming in 2011. Sci. Rep. 2013, 3. [CrossRef] [PubMed]

36. Soman, M.K.; Slingo, J. Sensitivity of the Asian summer monsoon to aspects of sea surface temperature anomalies in the tropical Pacific Ocean. Q. J. R. Meteorol. Soc. 1997, 123, 309-336. [CrossRef]

37. Wyrtki, K. Physical Oceanography of the Southeast Asia Waters. Available online: http:/ /escholarship.org/ uc/item/49n9x3t4\#page-3 (accessed on 2 July 2016).

38. Zagaglia, C.R.; Lorenzzetti, J.A.; Stech, J.L. Remote sensing data and longline catches of yellowfin tuna (Thunnus alalunga) in the Equatorial Atlantic. Remote Sens. Res. 2004, 93, 267-281. [CrossRef]

39. Ocean Color. Available online: https:/ / oceancolor.gsfc.nasa.gov/cgi/13 (accessed on 5 June 2016).

40. Environmental Data Connector. Available online: http://www.pfeg.noaa.gov/products/EDC/ (accessed on 17 June 2013).

41. Andrade, H.A.; Garcia, C.A.E. Skipjack tuna fishery in relation to sea surface temperature off the southern Brazilian coast. Fish. Oceanogr. 1999, 8, 245-254. [CrossRef]

42. Wolf, T.; McGregor, G. The development of a heat wave vulnerability index for London, United Kingdom. Weather Clim. Extrem. 2013, 1, 59-68. [CrossRef]

43. Pranowo, W.; Philips, H.; Wijffels, S. Upwelling Event 2003 Along South Java Sea and Lesser Sunda Islands. J. Segara 2005, 1, 63-67. 
44. Druon, J.N. Habitat mapping of the Atlantic bluefin tuna derived from satellite data: Its potential as a tool for the sustainable management of pelagic fisheries. Mar. Policy 2010, 34, 293-297. [CrossRef]

45. Syamsuddin, M.; Saitoh, S.-I.; Hirawake, T.; Syamsuddin, F.; Zainuddin, M. Interannual variation of bigeye tuna (Thunnus obesus) hotspots in the eastern Indian Ocean off Java. Int. J. Remote Sens. 2016, 37, 2087-2100. [CrossRef]

(c)

(C) 2017 by the authors; licensee MDPI, Basel, Switzerland. This article is an open access article distributed under the terms and conditions of the Creative Commons Attribution (CC BY) license (http:/ / creativecommons.org/licenses/by/4.0/). 